\title{
STATCOM FOR COMPENSATION OF SEIG FEEDING SINGLE-PHASE AND THREE-PHASE LOADS
}

\author{
SATYANARAYANA GORANTLA ${ }^{1} \&$ GOLI RAVI KUMAR ${ }^{2}$ \\ ${ }^{1}$ Associate Professor, Department of EEE, Anurag Engineering College and \\ Research Scholar, Acharya Nagarjuna University, Andhra Pradesh, India \\ ${ }^{2}$ Professor, Department of EEE, Bapatla Engineering College, Bapatla, Andhra Pradesh, India
}

\begin{abstract}
Now-a-days due to the drastically increased in use of nonlinear loads causes many power quality problems in power system network. Those problems are classified as reactive power problems, harmonics, voltage sags and swells. Out of these problems, harmonic problems are a major concern. Custom power devices proposed for mitigation of power quality in network. For compensation of harmonic, static compensator (STATCOM) is used. The paper presents the compensation of harmonic power quality issues using STATCOM for the system with singly-excited induction generator feeding single-phase load and three-phase loads. Proposed concept was developed using MATLAB/SIMULINK software and the results were presented to the system with STATCOM feeding single-phase load and three-phase loads.

KEYWORDS: STATCOM, Compensation, Singly Excited, Induction Generator, Single-Phase Load \& Three-Phase Load
\end{abstract}

Received: Jul 16, 2017; Accepted: Aug 05, 2017; Published: Sep 25, 2017; Paper Id: IJEEEROCT20171

\section{INTRODUCTION}

The increasing demand for electric power combined with depleting natural resources has led to the substantial improvements in the use of renewable energy systems such as wind and solar especially among the developing countries. Wind power is increasingly being viewed as a mainstream electricity supply technology. Grid connected wind electricity generation is showing the highest rate of growth of any form of electricity generation, achieving global annual growth rates in the order of $20-25 \%$.

It is increasingly important that wind generation continues to operate during periods of short circuit fault in the grid. The penetration of wind power has reached levels high enough to affect the quality and stability of the grid [3]. According to grid codes issued by utilities, tripping of wind turbines following grid fault is not allowed. Besides providing voltage support to the grid, mandatory reactive current supply is necessary [1]. Main ancillary services in a power system are power-frequency control and voltage control. These services must be provided by each generator connected to the grid. In order to provide the ancillary service of voltage, generators must have some reactive power capability as required by the corresponding grid codes [2, 4-8].

On the other hand, Static Synchronous Compensators (STATCOM) can be used to provide harmonic compensation when non-linear loads are present. There are various voltage source or current source inverter based on FACTS devices for flexible power control damping of power system and stabilization of wind generators, but in this work STATCOM based on a voltage source converter (VSC) is used to compensate the harmonics in power system due to non-linear loads of single phase and three-phase. 
The paper presents the compensation of harmonic power quality issues using STATCOM [9-10] for the system with singly-excited induction generator feeding single-phase load and three-phase load. Non-linear load induces harmonics in source components and the problem is addressed using STATCOM. STATCOM switches are controlled using gate drive circuit produced by using synchronous reference frame theory. The proposed work is simulated using MATLAB/SIMULINK and the results are presented.

\section{STATCOM WITH SINGLE-PHASE AND THREE-PHASE LOADS}

Figure 1 shows the system configuration of STATCOM with Singly Excited Induction Generator (SEIG) feeding single phase load and figure 2 shows the system configuration of STATCOM with Singly Excited Induction Generator (SEIG) feeding single phase load. STATCOM is a converter type FACTS device, which generally provides superior performance characteristics when compared with conventional compensation methods employing TSCs and TCRs. STATCOM based on VSC topology utilize either GTO or IGBT devices. In its simplest form, the STATCOM is made up of a VSC, and a DC energy storage device. The energy storage device is a relatively small DC capacitor.

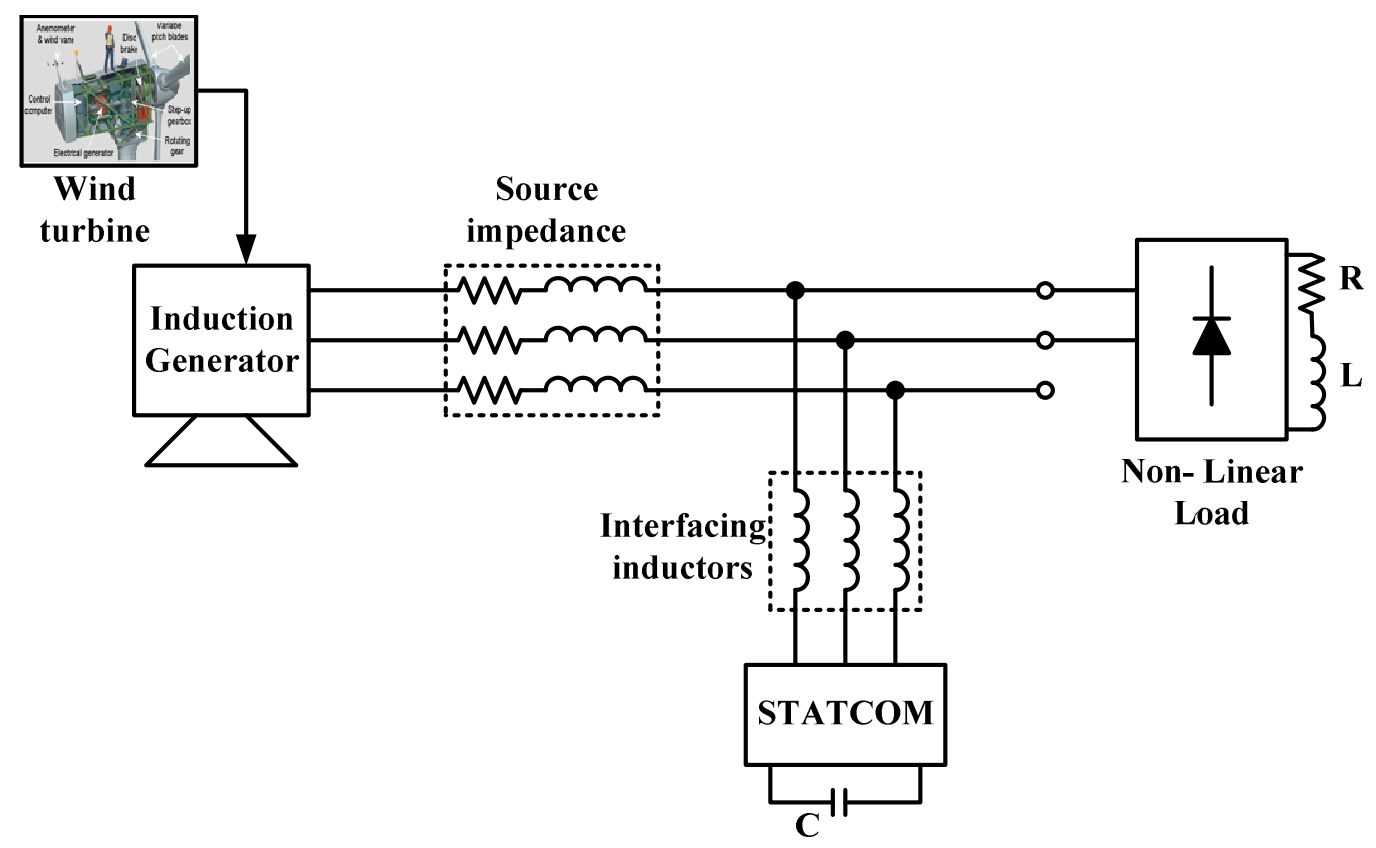

Figure 1: SEIG Feeding Single-Phase Non-Linear Load with STATCOM

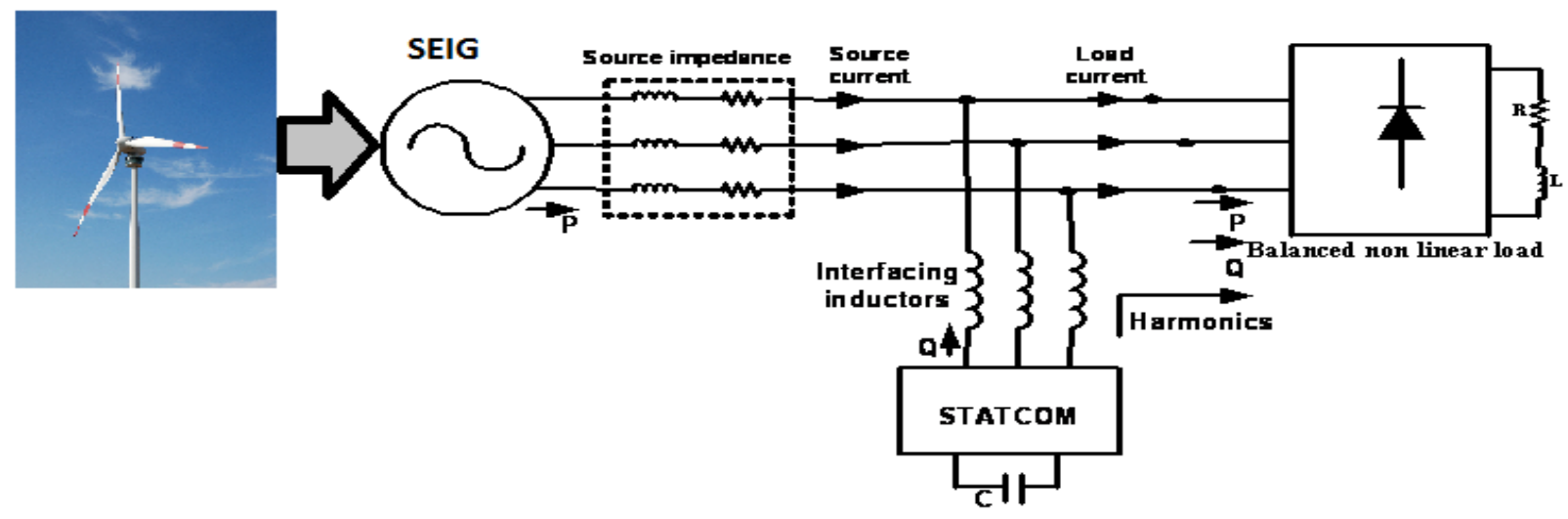

Figure 2: SEIG Feeding Three-Phase Non-Linear Load with STATCOM 


\section{CONTROL OF STATCOM}

In general, direct control is preferred where very fast voltage control is required (absence of capacitor dynamics) makes the response fast, but THD of converter voltage varies with modulation index, thereby producing more harmonic distortion in the voltage at low modulation index. On the other hand, indirect control operation is slow as AC output voltage of STATCOM varies according to variety of DC capacitor voltages (presence of capacitor dynamics makes the response slow) but harmonic injection in the power system bus voltage can be kept at a very low level by operating the inverter at a high modulation index where THD of converter voltage is lost.

Out of different control strategies, more efficient method of controlling the STATCOM is by the synchronous reference frame strategy, which uses co-ordinate transformations to generate the current reference. It employs the well known Clarkes Transformation and Parks Transformation for this purpose. Though, the transformations remind us of the primitive machine model concept, it may be noted that here there is no need to satisfy the condition of Power Invariance as the transformations are employed just to reduce the computations involved in generating the current reference and not to develop any equivalent system. Once the controller output is obtained, reverse transformations are employed to transform the quantities back to the actual three-phase system. Figure 3 shows the control strategy producing pulses to STATCOM.

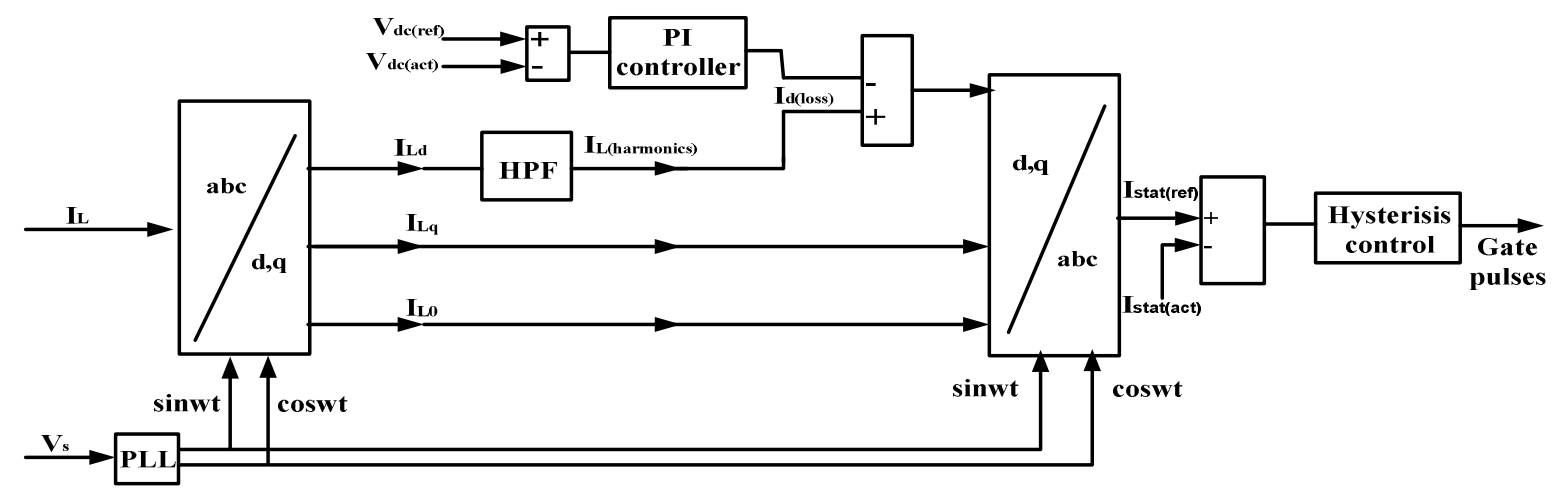

Figure 3: Control Strategy for STATCOM

\section{RESULTS AND DISCUSSIONS}

\section{Case 1: SEIG Feeding Single Phase Load}

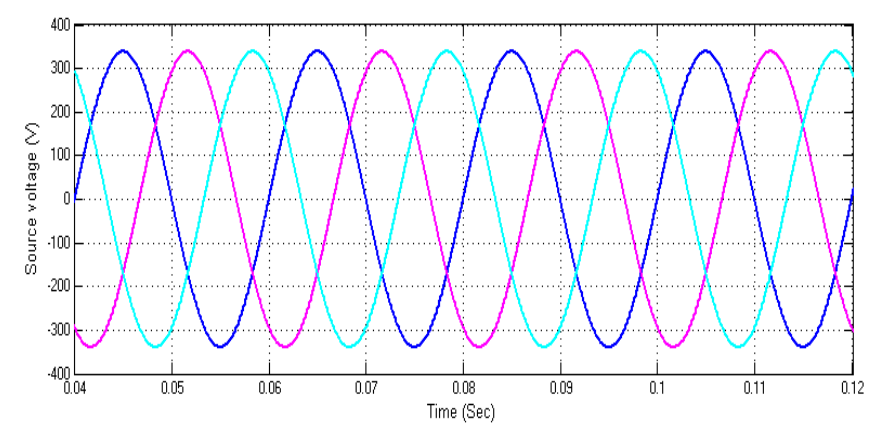

Figure 4: Source Voltage 


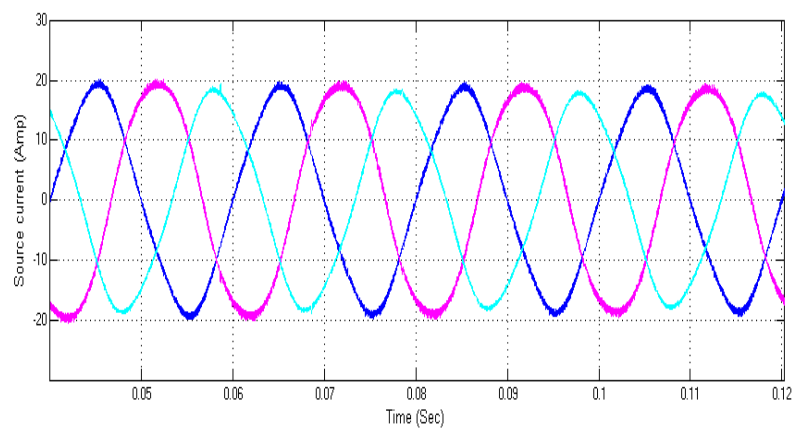

Figure 5: Source Current

Figure 4 shows the source voltage and figure 5 shows source currents with balanced linear load. Source voltage is maintained at $320 \mathrm{~V}$ with constant magnitude and source current is maintained at constant 20A magnitude sinusoidal in shape.

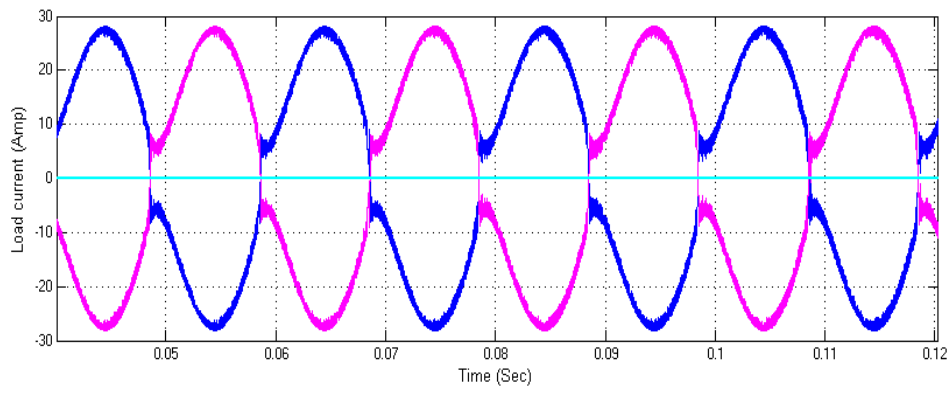

Figure 6: Load Current

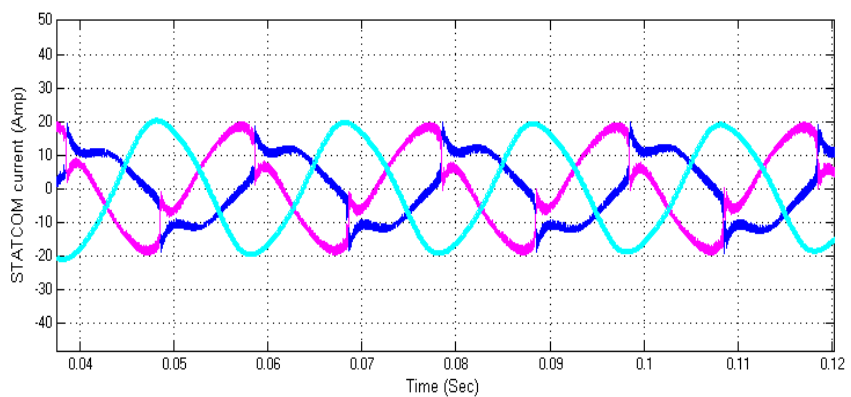

Figure 7: STATCOM Current

Load current maintained sinusoidal with linear load at load center is shown in fig 6 and STATCOM currents are shown in figure 7.

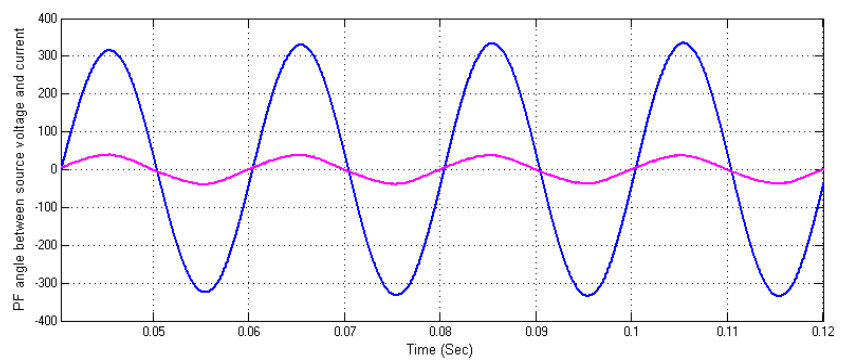

Figure 8: Power Factor Angle between Source Voltage and Current 


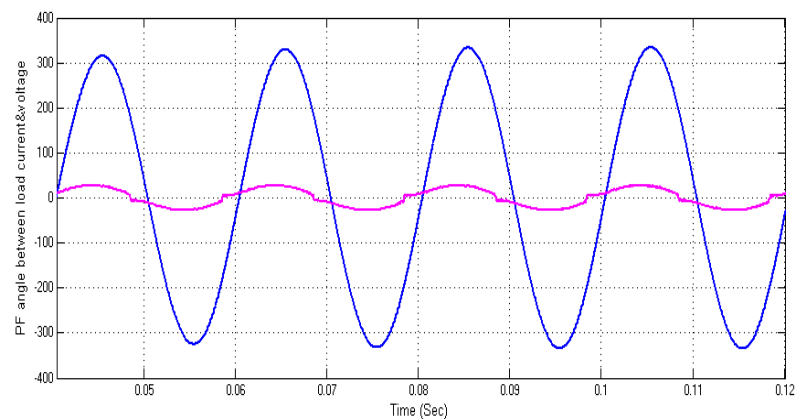

Figure 9: Power Factor Angle between Voltage and Load Current

The power factor angle between source current and source voltage maintained nearer unity as there is no phase difference between source voltage and current as shown in figure 8. Figure 9 shows Power factor angle between load current and load voltage with linear balanced load connected to the system.

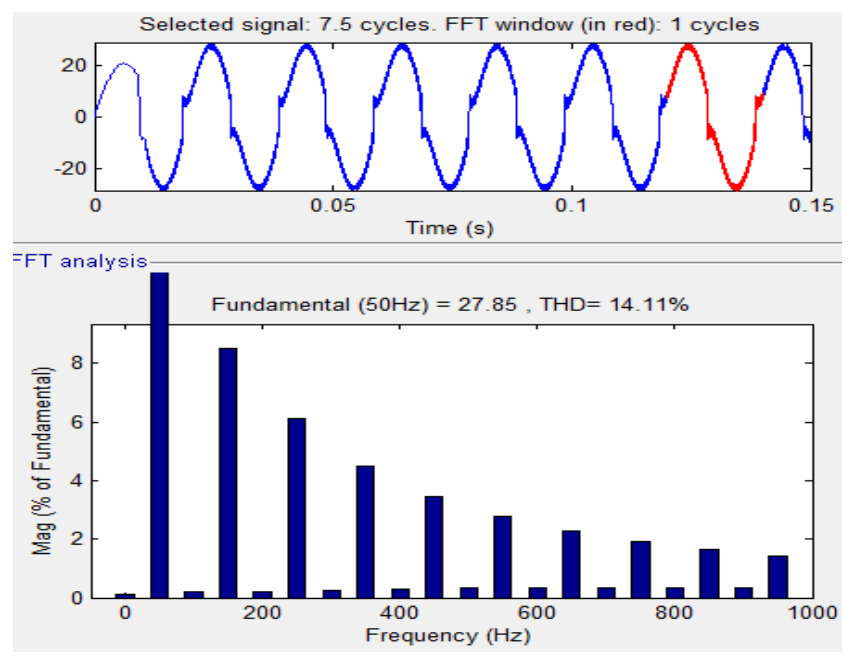

Figure 10: Source Current THD

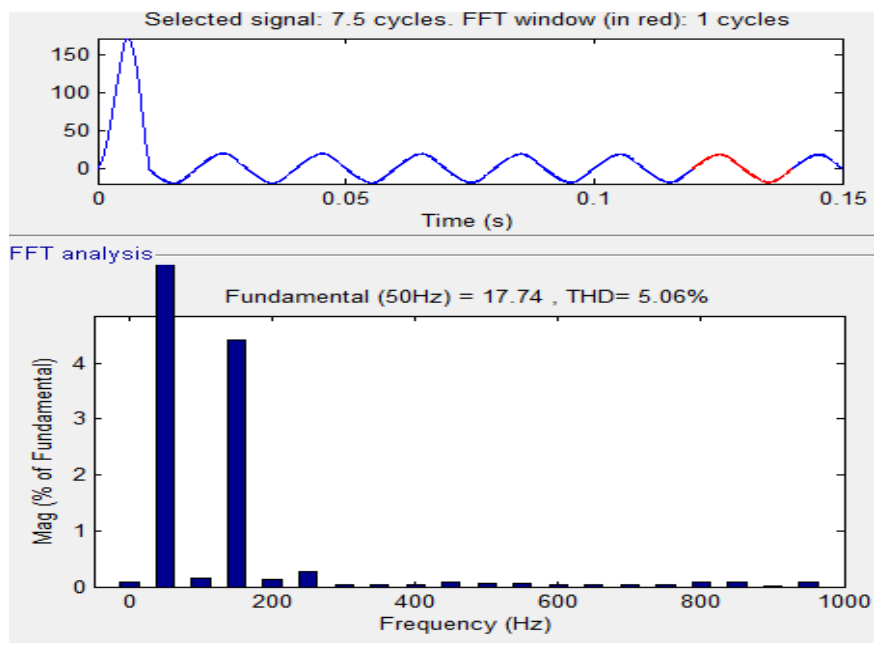

Figure 11: Load Current THD

Total harmonic distortion in load current is $14.11 \%$ as shown in figure 10 and total harmonic distortion in the source current is $5.06 \%$ as in figure 11 . Harmonic distortion is the current source is well maintained below the nominal value. 
Case 2: SEIG Feeding Three-Phase Load

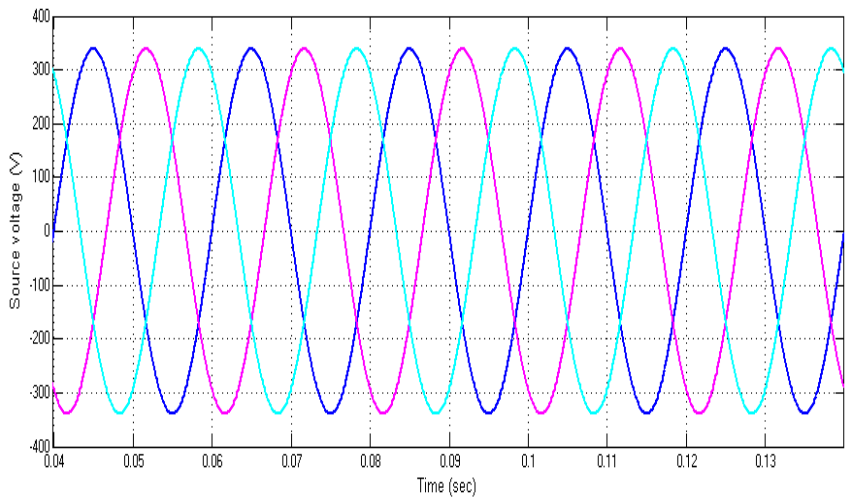

Figure 12: Source Voltage with Three-Phase Non-Linear Load

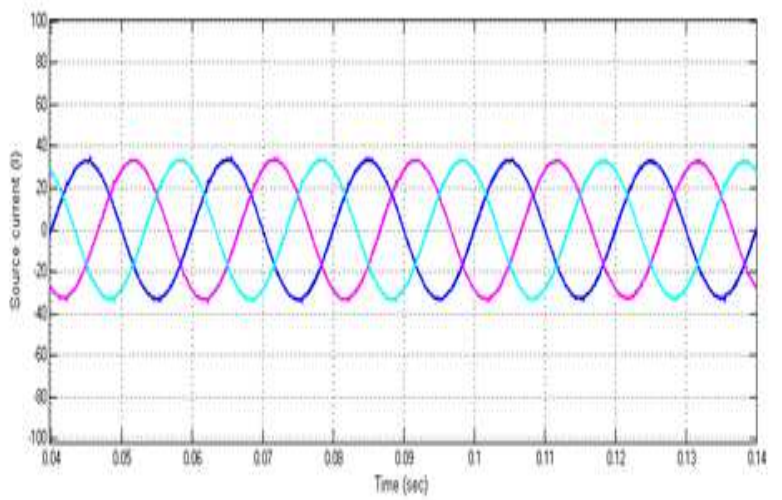

Figure 13: Source Current with Three-Phase Non-Linear Load

Figure 12 \& Figure 13 shows the Source voltage and current waveforms at balanced nonlinear load connected in Distribution system. The peak amplitude of source voltage is $320 \mathrm{~V}$ and the peak amplitude of the source current is $30 \mathrm{~A}$.

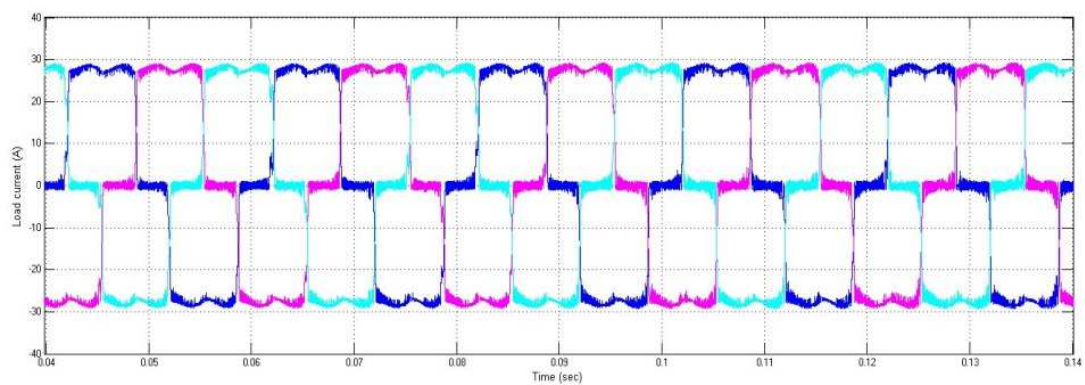

Figure 14: Load Current Waveform at Balanced Non-Linear Load

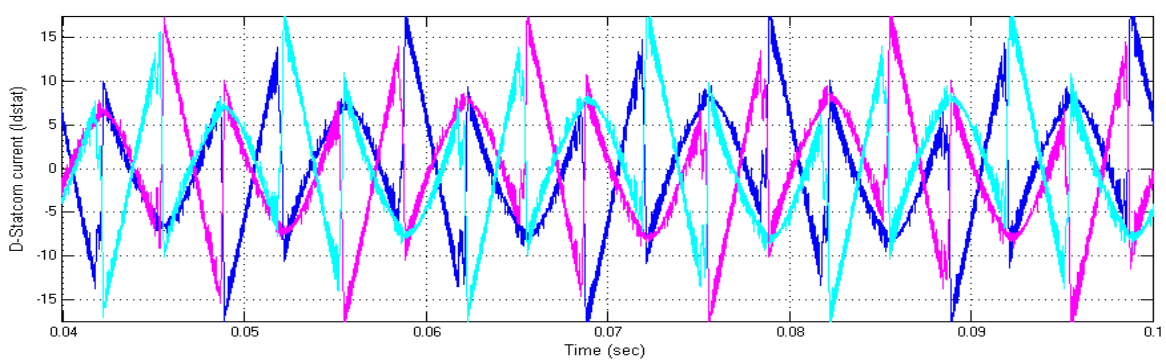

Figure 15: STATCOM Current Waveform at Balanced Non-Linear Load 
Figure 14 shows the load current waveforms at balanced, non linear load connected in Distribution system. Due to non linear load nature the current shape is square wave and it contains harmonics. Figure 15 shows the compensating STATCOM current waveforms at balanced nonlinear load connected in Distribution system. Stator supplies the harmonic current to a load, such that source current is sinusoidal.

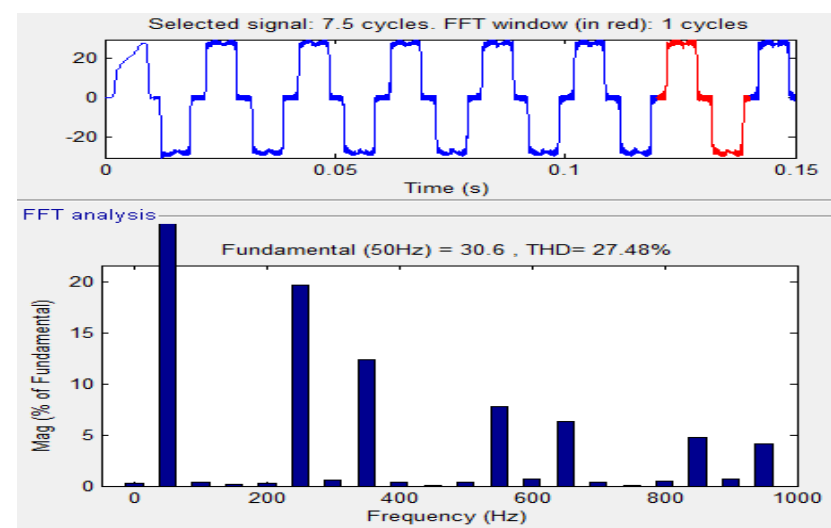

Figure 16: Load Current THD Plot at Balanced Non-Linear Load

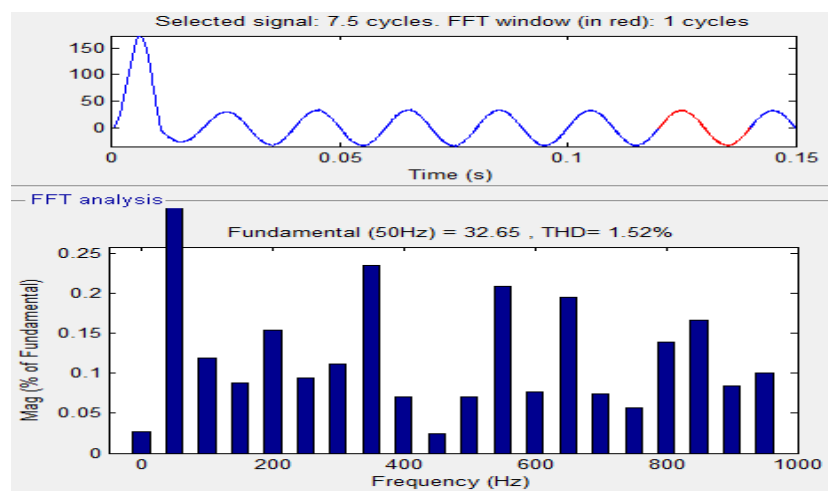

Figure 17: Source Current THD Waveform at Balanced Non Linear Load

Figure 16 shows the load current THD waveforms at balanced, Non linear load connected in Distribution system. The THD presented in load current is $27.48 \%$. Figure 17 shows the Source current THD plot when balanced, Non linear load is connected in Distribution system. The THD response was shown at $0.12 \mathrm{Sec}$ to $0.15 \mathrm{Sec}$ region of source current. The THD at source current is $1.52 \%$.

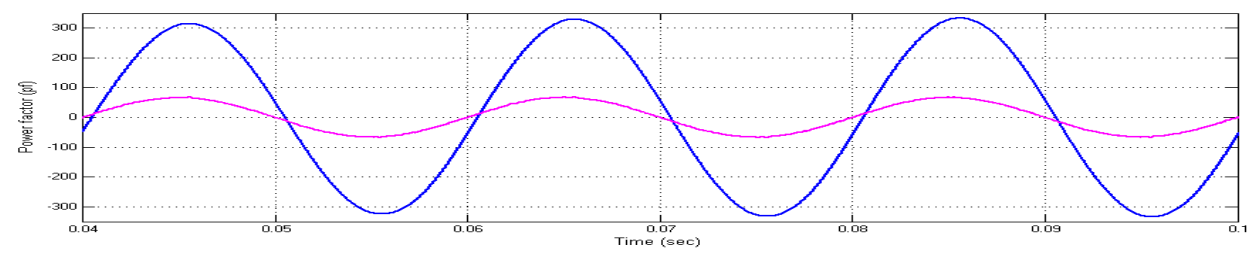

Figure 18: Power Factor Waveform at Balanced Non Linear Load

Figure 18 shows the Power Factor waveform of the angle between source voltage and current with Non linear load connected in Distribution system. Here the power factor is maintained around unity as no phase angle difference is present. Comparison of harmonic distortions in source current and load current of single-phase and three-phase loads are shown in table 1. THD comparative table indicates harmonic distortion in source current is well maintained within nominal value. 
Table 1: Comparison of THD in Source and Load Currents

\begin{tabular}{|c|c|c|}
\hline THD & Source Current & Load Current \\
\hline Single-Phase Non-Linear Load & $5.06 \%$ & $14.11 \%$ \\
\hline Three-Phase Non-Linear Load & $1.52 \%$ & $27.48 \%$ \\
\hline
\end{tabular}

\section{CONCLUSIONS}

The paper presents the effectiveness of compensating harmonics in source currents due to the presence of nonlinear loads. This paper presents the performance of STATCOM when SEIG is feeding single phase and three phase nonlinear loads. Harmonic distortion is well maintained within the nominal value less than 5\% in source current even with the presence of non-linear loads of single phase and three phase type with connected STATCOM at the point of common coupling. With the reduction of harmonic distortion, the source currents are maintained nearer sinusoidal with less distortion and thus does not affects other sensitive loads connected at PCC.

\section{REFERENCES}

1. Zhao Liu, Bangyin Liu, Shanxu Duan, and Yong Kang, “A novel DC capacitor voltage balance control method for multilevel STATCOM", IEEE Transactions on Power Electronics, Vol. 27, No. 1, January 2012.

2. Parag Kanjiya, Vinod Khadkikar, and Hatem H. Zeineldin,-A Non iterative Optimized Algorithm for Shunt Active Power Filter Under Distorted and Unbalanced Supply Voltages\|, IEEE Transactions on Industrial Electronics, vol. 60, no. 12, pp. 5376- 5390 December 2013.

3. IEEE Standard Definitions for the Measurement of Electric Power Quantities under Sinusoidal, Non sinusoidal, Balanced, or Unbalanced Conditions, IEEE Std. 1459-2010.

4. Arindam Ghosh and Gerald Ledwich, Power Quality Enhancement Using Custom Power Devices, Kluwer Academic Publishers, 2002.

5. S. M.-R. Rafiei, H. A. Toliyat, R. Ghazi, and T. Gopalarathnam, -An optimal and flexible control strategy for active filtering and power factor correction under non-sinusoidal line voltages, $\|$ IEEE Trans. Power Del., vol. 16, no. 2, pp. 297-305, Apr. 2001 .

6. Amir H. Norouzi, A.M. Shard, “A Novel Control Scheme for the STATCOM Stability Enhancement”, 2003 IEEE PES Transmission and Distribution Conference and Exposition, Sept. 2003.

7. G. E. Ahmed, Y. S. Mohmed and O. M. Kamel, "Optimal STATCOM controller for enhancing wind farm power system performance under fault conditions," 2016 Eighteenth International Middle East Power Systems Conference (MEPCON), Cairo, Egypt, 2016, pp. 226-233.

8. E. R. Mauboy, T. T. Lie and T. N. Anderson, "Stability enhancement of a power system with wind generation using ANN based STATCOM," 10th International Conference on Advances in Power System Control, Operation \& Management (APSCOM 2015), Hong Kong, 2015, pp. 1-6.

9. H. Samet and M. A. Jarrahi, "A comparison between SVC and STATCOM in flicker mitigation of electric arc furnace using practical recorded data," 2015 30th International Power System Conference (PSC), Tehran, Iran, 2015, pp. 300-304.

10. T. Paulraj, I. S. Sherin and M. A. Prakash, "Mitigation of power loss in transmission and distribution line using STATCOM," 2016 International Conference on Advanced Communication Control and Computing Technologies (ICACCCT), Ramanathapuram, India, 2016, pp. 432-435. 